\title{
Turbulence characteristics of favorable pressure gradient flows in gravel-bed channel with vegetated walls
}

\author{
Elham Fazel Najafabadi ${ }^{1}$, Hossein Afzalimehr ${ }^{1}$, Jueyi Sui ${ }^{2 *}$ \\ ${ }^{1}$ Department of Water Engineering, Isfahan University of Technology, Isfahan, 84156-83111, Iran. \\ ${ }^{2}$ Environmental Engineering Program, University of Northern British Columbia, 3333 University Way, Prince George, BC, Canada. \\ ${ }^{*}$ Corresponding author. E-mail: jueyi.sui@unbc.ca
}

\begin{abstract}
Field observations showed that in many gravel-bed rivers, rice stems and gravel interact with each other and affect the flow structure. This calls to conduct research in more details in laboratory to better understand impacts of interaction between rice stems and gravel bed rivers on the flow structure. The outcome of such investigations can improve the estimation of drag coefficient in hydrodynamic models. Experiments were carried out in a flume with gravel bed and the vegetated vertical flume walls to investigate turbulence characteristics under favorable pressure gradient flows. Results showed that the stress fraction involves both the sweep and ejection dominance near the vegetated flume walls, showing no negative Reynolds shear stress near water surface. The values of exuberance ratio play a significant role on the magnitude of the Reynolds shear stress which varies with the distance from the vegetation. Quadrant analysis reveals that a major part of the momentum flux is transported during a short period of strong turbulence activity near the bed at the central axis. Augmentation of the hole size makes difference between contributions of sweep and ejection with those of the outward and inward interactions near the bed, however, the hole size doesn't play any role near the water surface.
\end{abstract}

Keywords: Favorable pressure gradient flow; Vegetation; Gravel; Quadrant analysis; Stress fraction; Reynolds stress.

\section{INTRODUCTION}

Favorable pressure gradient (FPG) flow in which velocity increases and depth decreases in flow direction, occurs in many natural channels/rivers, such as flow over bed forms and meandering rivers. Literature review in FPG flow reveals that the distributions of velocity, Reynolds shear stress and turbulence intensities under condition of steady flow have been investigated over smooth bed (Kachwal et al., 2012); over two dimensional bed forms (Mazumdar et al., 2009); over gravel-bed channels (Afzalimehr and Rennie, 2009; Afzalimehr et al., 2010; Song and Chiew, 2001); over sand bed with sediment transport conditions (Emadzadeh et al., 2010; Jamieson et al., 2013; Liu et al., 2012; Rennie et al., 2002); over cobble bed (Afzalimehr, 2010); and over vegetated bed (Afzalimehr et al., 2011; Ghisalberti and Nepf, 2006; Järvelä, 2005; Luhar et al., 2008). Yue et al. (2007) conducted a case study in a flume that the channel bed covered by canopy. By using PIV, they did the measurements near the canopy. They compared LES and measurements near the tip of the canopy by means of a quadrant-hole analysis of turbulent kinetic energy, vorticity, and dissipation rate. The simulation results confirmed that sweeps contribute the largest fraction of turbulent kinetic energy, vorticity, and dissipation rate inside the plant canopy; whereas the magnitudes of the vorticity and dissipation rate at the top of the canopy are highest in the first quadrant.

All these studies under the FPG flow condition gave almost similar results for both Reynolds stress and turbulence intensities which are different from those for zero pressure gradient (ZPG) flow.

Turbulence structure in uniform open-channel flow over rough beds has been investigated by many researchers (e.g., Dey and Nath, 2010; Graf and Altinakar, 2002). Properties of the flow over rough beds influence the turbulence structure, as pointed out by Leonardi et al. (2003). Identification of turbulent flow structure in open channels is of primary interest in environmental hydraulics since the turbulence plays an important role in mass and momentum exchanges.Coherent structures distribute both particles and pollutants across the whole water column much faster than small scale turbulence (Hurther et al., 2002). Coherent structures have a short life span, and they cannot be identified by means of a time-averaged analysis. Therefore, it requires an investigation based on measurements considering changes with both time and location. In laminar and transitional flows, coherent structures occur periodically, whereas in turbulent flows they occur randomly and change with both location and time. Hence, conditional sampling and statistics techniques have to be used in the detection and characterization of coherent structures. The conditional statistics technique may be applied to quasi instantaneous velocity samples obtained from the ADV measurements. Several investigators applied conditional statistics to turbulence studies ( $\mathrm{Lu}$ and Willmarth, 1973; Nakagawa and Nezu, 1977; Raupach, 1981). Literature review in coherent structures indicated the importance of conditional statistics in sediment transport (Cellino and Lemmin, 2004; Keylock et al., 2014); and obstacle marks (Maity and Mazumder, 2012, 2013). However, the turbulence structure in FPG flow over a rough bed in open channels, has received less attention compared to the ZPG flow because it is often assumed that flow is uniform or quasi uniform in river engineering studies.

Understanding the influence of FPG flow on the turbulence structure is very important for evaluating the resistance to flow and transport of sediment in rivers with gravel bed and vegetated walls. Consequently, a more detailed study on the interaction of the FPG flow in gravel-bed channels with vegetated walls is needed to improve our understanding in determining key parameters such as Reynolds stress in environmental hydraulic. To our knowledge, no study has been reported on coherent turbulence structure in a gravel-bed channel with vegetation in vertical walls for FPG flow. In rivers, flow characteristics, such as non-uniformity in velocity and Reynolds stress distributions, are affected by aquatic vegetation, showing the necessity to consider these variations in hydraulic modelling. 
The objective of the present study is to investigate the turbulence characteristics of FPG flows in a flume with a gravel bed and vegetated vertical walls, namely, 1) the impact of FPG flow in a flume over gravel bed and vegetated flume walls on the distributions of stress magnitudes; 2) the relationship between exuberance ratio and magnitude of Reynolds stress at different normalized flow depth $(y / h, y$ is a distance from the bed and $h$ is the flow depth) and different quadrant holes (threshold level in the Reynolds stress signals).

\section{BACKGROUND}

\section{Conditional statistics of Reynolds shear stress}

Coherent structures have a short life span and cannot be identified by means of a time-averaged analysis. Thus, the coherent structure changes with both time and locations and should be examined. It is found that fluid motion near a bed is not completely chaotic in nature, but it is a clear "sequence of ordered motion". Such coherent motion is called the bursting process. Conditional sampling and statistics techniques are used to detect and characterize the coherent structures. One of the widely used conditional sampling techniques is the quadrant analysis of the Reynolds shear stress.

Results of the quadrant analysis can provide information about the processes of turbulence production by sorting the instantaneous values of the Reynolds stress, $u$ ' $w$ ' into four categories according to the sign of the two fluctuating components, where $u^{\prime}$ and $w^{\prime}$ are velocity fluctuation components in the longitudinal and the vertical directions respectively. Accordingly, turbulent events are defined by the four quadrants as outward interactions $\left(i=1 ; u^{\prime}>0 ; w^{\prime}>0\right)$, ejections $\left(i=2 ; u^{\prime}<0 ; w^{\prime}>0\right)$, inward interactions $\left(i=3 ; u^{\prime}<\right.$ $\left.0 ; w^{\prime}<0\right)$, and sweeps $\left(i=4 ; u^{\prime}>0 ; w^{\prime}<0\right)$. Results in quadrants 2 and 4 mean the positive downward momentum flux, and are involved in turbulence near-bed bursting. The quadrant analysis has been applied to canopy turbulent flows, e.g. wheat and bushes, over rigid and flexible canopies (Afzalimehr et al., 2011; Ghisalberti and Nepf, 2006) over intensive grass.

At any point in a steady flow, the contribution to the total Reynolds shear stress from quadrant $i$, excluding a hyperbolic hole region of size $H$, is given by (Yue et al., 2007)

$$
\left\langle u^{\prime} w^{\prime}\right\rangle_{i, H}=\lim \frac{1}{T} \int_{0}^{T} u^{\prime}(t) w^{\prime}(t) I_{i, H}\left[u^{\prime}, w^{\prime}\right] d t
$$

where $T$ is the sampling time period, and square brackets denote a conditional average and the indicator function $I_{i, H}$ is defined as (Yue et al., 2007)

$$
I_{i, H}\left(u^{\prime}, w^{\prime}\right)= \begin{cases}1 & \text { if }\left(u^{\prime}, w^{\prime}\right) \text { is in ith quadrant and } \\ & \text { if }\left|u^{\prime} w^{\prime}\right| \geq H\left|\overline{u^{\prime} w^{\prime}}\right| \\ 0 & \text { otherwise }\end{cases}
$$

In which parameter $H=$ hole size, is a threshold level in the Reynolds stress signals which enables to extract the values of $\left|u^{\prime} w^{\prime}\right|$ from the whole set of data which are greater than $H\left|\overline{u^{\prime} w^{\prime}}\right|$. Using (2), the contribution to Reynolds stress ( $u$ 'w') can be extracted from each quadrant for various hole sizes. Steiner et al. (2011) found that the number of events and event duration decreases as $H$ increases and thus the contribution to momentum and heat flux decreases. Lu and Willmarth (1973) claimed that when the hole size $H$ becomes large, there are only two contributions. One is $\widetilde{u} v_{2}$ and the other one comes from the 'hole' region. Thus, the burst-like events in the turbulent boundary layer are important. For a hole size of $H=4.5$, which $|u v|>10|\overline{u v}|$, there is still a contribution of about $15-30 \%$ to $\overline{u v}$

from the second quadrant, i.e. $\widetilde{u} v_{2} / \overline{u v} \approx 0.15-0.30$. At this level there are nearly no contributions from the other three quadrants. As pointed out by many researchers, the $H$ value is beyond the limit of 0 to 8 . As claimed by Yue, et al. (2007), the stress fraction is given as following:

$S_{i, H}=\left\langle u^{\prime} w^{\prime}\right\rangle_{i, H} /\left|\overline{u^{\prime} w^{\prime}}\right|$

By definition, $S_{i, H}<0$ if $i$ is even (sweeps and ejections) and $S_{i, H}>0$ if $i$ is odd (outward and inward contributions).

To assess the strength of signals of turbulent events, the duration of the turbulent events is also computed by suing following equation (Yue et al., 2007)

$D_{i, H}=\frac{1}{T} \int_{0}^{T} I_{i, H}\left[u^{\prime}, w^{\prime}\right] d t$

$D_{i, H}$ is the ratio of the number of events at hole sizes exceeding a particular level to the total number of turbulent events.

The quadrant fractions obtained from (3) do not consider the event duration. The normalized magnitude of a quadrant event, which considers the event duration, is determined as (Yue et al., 2007)

$S_{i, H}^{D}=S_{i, H} / D_{i, H}$

The above equation can be used to assess the strength of event signals compared to the event fraction. All calculations for assessing the contribution of each quadrant to the Reynolds shear stress were performed by a written program in Matlab. In this study, the value of hole size is determined based on satisfaction of the equation (2). The range of $\mathrm{H}$ used in from 0 to 8 for our analysis as considered in other studies (Afzalimehr et al., 2011).

\section{EXPERIMENTAL SETTING UP}

Experiments were carried out in a $8 \mathrm{~m}$-long, $0.4 \mathrm{~m}$-wide, and 0.6 m-deep rectangular flume in the Hydraulics Laboratory of Isfahan University of Technology, Iran. A tail gate located at the end of the flume controlled water level during the experiments. A pump with a maximum discharge of $50 \mathrm{l} / \mathrm{s}$ circulated water from a sump. An electromagnetic flow-meter was installed in the supply conduit connected to the flume to continuously measure the discharge passing through the channel. Water depth was measured by using mobile limnimeter along the flume. The value of $d h / d x$ which is used to calculate the pressure gradient parameter $(\beta)$ was determined from the continuous water surface profile, adjusted by a spline fit technique to the flow depth measurements. To minimize the errors, the flow depths measurements along the flume center line were taken in this study. For each run, 20 measurements were obtained along the entire flume.

The gravel particles were used with a median diameter $\left(d_{50}\right)$ of $20 \mathrm{~mm}$ and the geometric standard deviation $\sigma_{g}=\left(d_{84} / d_{16}\right)^{0.5}$ of 1.14 , where $d_{84}$ and $d_{16}$ are $84 \%$ and $16 \%$ finer particle diameters, respectively. 
Rice is cultivated around of many Iranian rivers; however, no information is available on the impact of rice stems on flow structure. To understand the interactions of rice stems in walls, gravel bed and FPG flow on turbulence characteristics, the flume walls were covered by rice stems by $0.74 \mathrm{~cm}$ mean diameter of stems that collected from the floodplains of rivers in the central Iran. Rice, which planted in wet environment, had 30\% submergence in floodplains. The planting density (a linear length along the flume) was 400 stems $/ \mathrm{m}$ with $5 \mathrm{~mm}$ thickness with the degree of submergence of vegetation in water from 0.42 to 0.46 without any flexibility. To prevent the vegetation cover from washing away from on the flume walls, they were stuck and stitched by a thin cotton wire over a plastic carpet and it was stuck to the flume walls (Figure 1).

A down looking Acoustic Doppler Velocimeter (ADV), developed by NORTEK was used to measure the instantaneous three-dimensional velocity components. The ADV was set on tracks above the flume and could be moved easily in both vertical and horizontal directions. The measurement error of mean velocity is less than $\pm 2.5 \mathrm{~mm} / \mathrm{s}$ (or $\pm 1 \%$ ). Velocity measurements were recorded for each point with a sampling frequency of $200 \mathrm{~Hz}$ and a sampling volume of $5.5 \mathrm{~mm}^{3}$. The duration for each measurement was 120 seconds, resulting 24000 instantaneous velocity data for each point. The correlation and signalto-noise ratio (SNR) were recorded in the ADV file for each probe beam. To obtain high quality data from the ADV, SNR values must be greater than $5 \mathrm{~dB}$ for mean flow velocity measurements and greater than $15 \mathrm{~dB}$ for measurements of instantaneous velocity or turbulence quantities. "Win ADV" software was used to filter data. The measurements with average SNR values less than or equal to $15 \mathrm{~dB}$ and average correlation less than or equal to $70 \%$ were filtered out. The velocity data collected by ADV were analyzed to compute the mean flow, Reynolds stress and turbulence characteristics for each point.

For each velocity profile, the point with the largest velocity measured is defined as the maximum velocity, and determination of shear velocity is referred to the logarithmic law. The flow velocity distribution over gravel beds can be presented near the bed (the inner region $y / h<0.2$ ) by the logarithmic law as follow (Graf and Altinakar, 1993):

$$
\frac{u}{u_{*}}=\frac{1}{\kappa} \ln \left(\frac{y+0.2 d_{50}}{d_{50}}\right)+C
$$

where $u *$ is the shear velocity, $\kappa$ is von Karman's constant taken as $\kappa=0.4, d_{50}$ is the median gravel size and $C$ in the constant integration. The bottom slope was fixed by varying the thickness of the gravel layer along the flume to obtain a slope of $-1.5 \%$ (i.e. minimum thickness was $3 \mathrm{~cm}$ at the flume entrance and maximum thickness was $14.5 \mathrm{~cm}$ at the downstream end of flume). The negative bottom slope demonstrating the reverse slope can generate an accelerating flow. Flow discharge of 25 $1 / \mathrm{s}$ is set up for this study. To investigate the influence of vegetated walls on velocity and Reynolds stress at each section, flow velocity was measured at distances of $D=0.03$ and $0.20 \mathrm{~m}$ from the vegetated wall. The number of points for velocity measurements in each profile ranged from 29 to 34, depending on the depth of water.

To verify the occurrence of the FPG flow, depth variation and flow velocity distribution must be measured at different sections. The channel reach for measurement was located downstream of the section where the upper limit of boundary layer reaches the water surface. Also fully developed uniform flow occurs at a distance of $x=4.2 \mathrm{~m}$ downstream from the flume entrance for a water depth of $0.25 \mathrm{~m}$. In this study, both flow depths and velocity distributions were measured at three sections $5.0 \mathrm{~m}, 5.5 \mathrm{~m}$, and $6.0 \mathrm{~m}$ from the flume entrance. To have the favorable pressure gradient, it is necessary to present the effect of longitudinal pressure gradient. Graf and Altinakar (2002) defined a dimensionless pressure gradient $(\beta)$ as follow (Kironoto and Graf, 1995)

$$
\beta=\frac{h}{\tau_{0}} \frac{\partial p^{*}}{\partial x}=\frac{h}{\tau_{0}}\left[\gamma\left(-S_{0}+\frac{\partial h}{\partial x}\right)\right]
$$

In which $h$ is flow depth, $\tau_{0}$ is the bed shear stress, $\gamma$ is specific gravity of water, $S_{0}$ is the bed slope and $\partial h / \partial x$ is the flow depth variation along the flume. For the ZPG flow, $\partial h / \partial x$ is zero; therefore $\beta$ equals to -1 . It is showed that $\beta$ remains constant for equilibrium flow, showing approximately constant values for $\beta$ along a flume. For this experimental study, the calculated $\beta$ ranged from -5.68 to -5.92 , confirming the equilibrium flow. In addition, when $\beta>-0.5$ the flow is in equilibrium, confirming that for the present study the flow is in equilibrium. The equilibrium flow (constant $\beta$ ) makes possible to generalize the results for flows with pressure gradient because such a flow does not depend on its upstream sections and allows for drawing the results based on experimental data at a section (Graf and Altinakar, 2002). Accordingly, in this study, only the results of the last cross section ( $6 \mathrm{~m}$ from the entrance) and different dis-
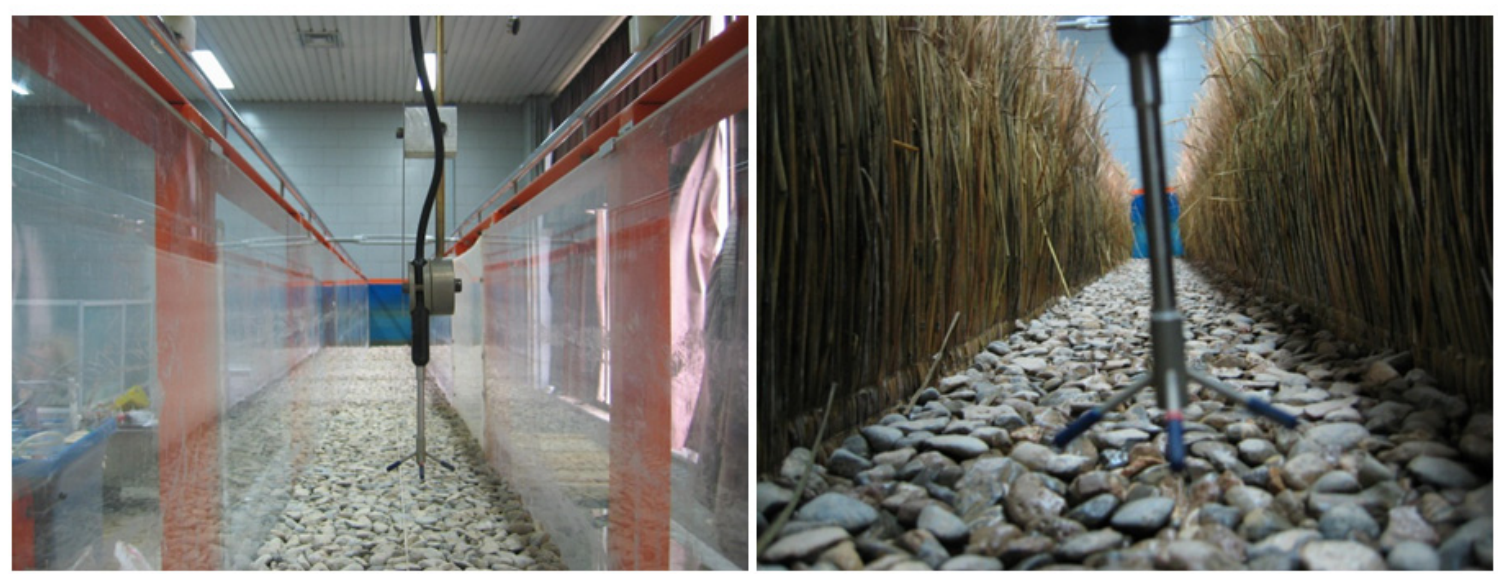

Fig. 1. Experimental setup. 
tances $(D=0.03 \mathrm{~m}$ and $0.20 \mathrm{~m})$ from the vegetated walls will be investigated and discussed. In this section, the water depth was $25.5 \mathrm{~cm}$.

\section{ANALYSIS AND RESULTS \\ Reynolds shear stress and turbulence intensities}

Figures 2a, 2b, 2c \& 2d represent three components of velocity, shear stress and turbulence intensities respectively for both FPG and ZPG flows. Due to limited space it is not shown in these figures that the two components of $u$ 'v', and $v^{\prime} w^{\prime}$ have small magnitude near zero. However, near the bed with a water depth of $y / h<0.2$, the absolute values of dimensionless shear stress were increased up to 0.8 . This result can be due to narrow experimental flume and occurrence of secondary currents. As a consequence, since the third component of shear stress $\left(u^{\prime} w^{\prime}\right)$ is very important, the main task of our research is to study $u$ ' $w$ '. Figure $2 \mathrm{~b}$ displays the vertical profiles of Reynolds shear stress for both FPG and ZPG flows. For ZPG flow, the maximum Reynolds stress occurred at the bed, and then decreased toward the free surface with zero value at $y / h \approx 0.65$ and negative values near the water surface. For FPG flow at the centerline of the flume, the maximum Reynolds stress occurred near the bed $(y / h$ $=0.03)$. Similar to changes in the Reynolds stress in the ZPG flow, it decreased toward the free surface with zero value at $y / h$ $\approx 0.61$, and smaller negative values zone then the uniform flow near the water surface. These findings are not in agreement with results of Graf and Altinakar (2002) and Song and Chiew (2001) because they did not obtain any negative Reynolds stress near the water surface. In addition, they claimed that a concave form for the Reynolds shear stress distribution over gravel-bed flume with glass walls. Reynolds stress distribution displays a Z-shape pattern near the vegetation cover, showing two peaksone at $y / h=0.16$ and another at $y / h=0.67$. At these two peak

(a)
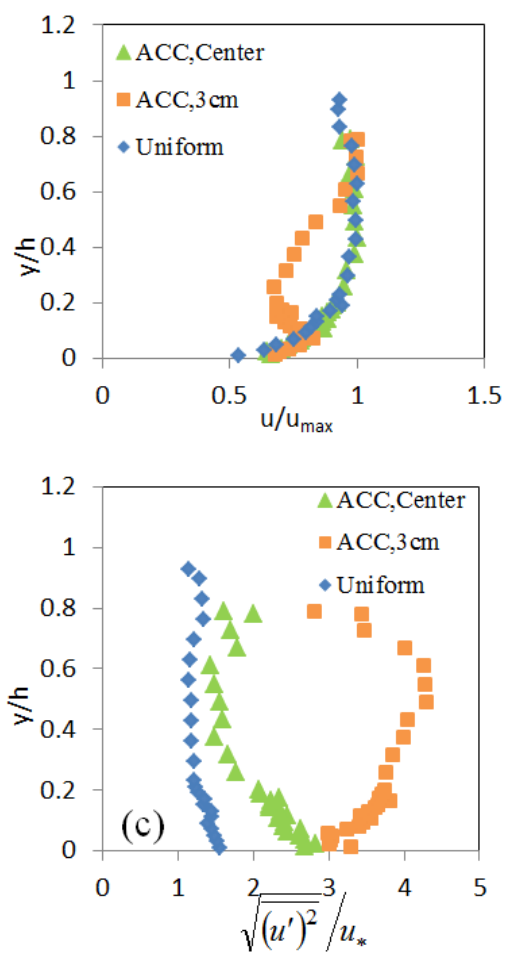

points the ratio of negative to positive contributions to the momentum flux are maximum and minimum, respectively. As it is mentioned in the experimental setting up, a down looking Acoustic Doppler Velocimeter (ADV) was used to measure the instantaneous three-dimensional velocity components. This device can't be used to conduct measurement for the $5 \mathrm{~cm}$ top layer of the water surface. According to the decreasing trend of shear stress distribution, it seems it can be either zero or close to zero, at the water surface.

The stream-wise turbulence intensity component $\left(\sqrt{\overline{\left(u^{\prime}\right)^{2}}} / u_{*}\right)$ was presented for the FPG flow at the centerline and $3 \mathrm{~cm}$ from vegetation cover, as well as for the ZPG flow in Figure 2c. Also, the vertical component of turbulence intensity $\left(\sqrt{\left(w^{\prime}\right)^{2}} / u_{*}\right)$ was presented in Figure 2d. One can see from these figures that the distribution of turbulence intensity has the concave pattern for both FPG and ZPG flows at the centerline channel. These findings confirm the results of Graf and Altinakar (2002) and Song and Chiew (2001). However, for the FPG flow, the occurrence of strong secondary currents by the joint effects of aspect ratio and vegetation caused a convex distribution for both $\sqrt{\overline{\left(u^{\prime}\right)^{2}}} / u_{*}$ and $\sqrt{\overline{\left(w^{\prime}\right)^{2}}} / u_{*}$ near the vegetated walls $(D=3 \mathrm{~cm})$.

\section{Quadrant analysis}

Figure $3 \mathrm{a}$ shows the dominant turbulent events over the entire flow depth at the central axis of the flume. It is found that the role of ejection and sweep decreases as roughness increases, whereas the contributions of outward and inward to the Reynolds stress become significant. The results of our research indicate that for $H$ ranging from 0 to 8 (Figure 4 shows the hole
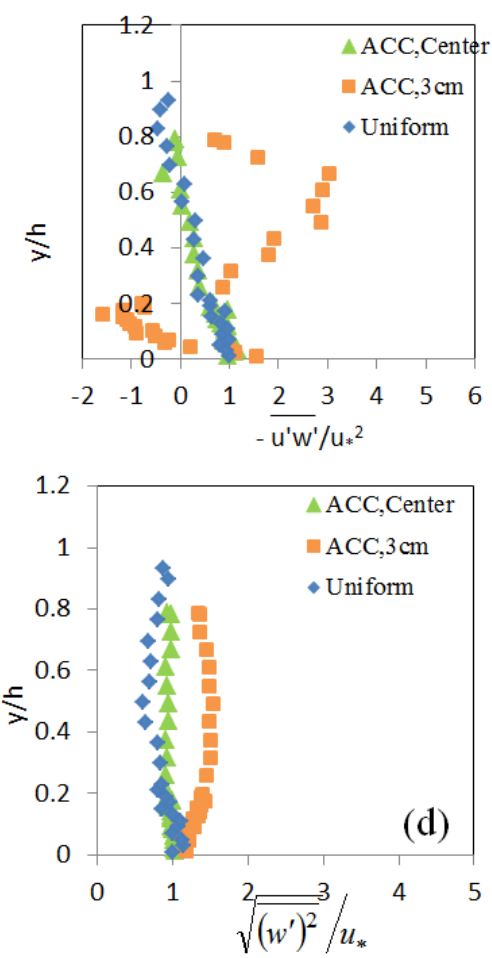

Fig. 2. (a), (b) \& (c) Reynolds stress and (d) intensity turbulence distributions; Comparision for centerline channel \& $3 \mathrm{~cm}$ from vegetated bank for accelerating, and uniform (centerline) profiles. 
(a)
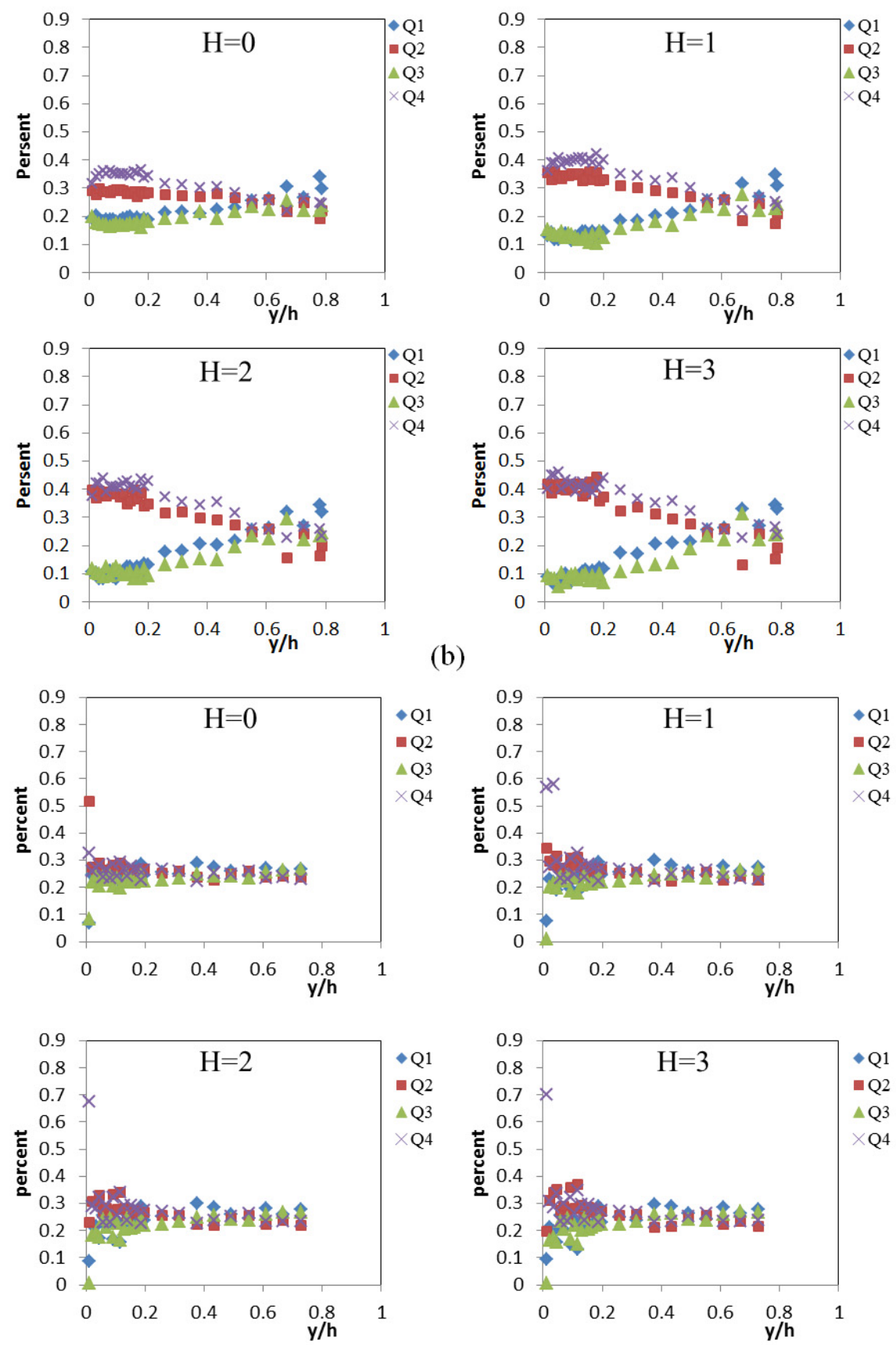

Fig. 3. Percentage of velocity fluctuations $\left(u^{\prime}\right.$ and $\left.w^{\prime}\right)$ for each quadrant $(i=1,2,3$ and 4$)$; a) at the center of flume and b) near the vegetated bank $(D=3 \mathrm{~cm})$.

sizes $H$ only from 0 to 3 due to space limitation), two regions can be distinguished over the entire flow depth: the first region with a water depth of $0<y / h<0.55$, and the second region with a water depth of $0.55<y / h<0.80$ (the maximum flow depth where data collected by ADV). In the first region, the dominant event is sweep, followed by ejection, then outward and inward interactions respectively. Also, in the first region, sweep and ejection are the most frequent events while the outward and inward events have the shorter time fraction with smaller shear stress than the absolute values of the sweep and ejection contributions. This indicates that the momentum transfer between the flow and channel bed is mostly carried by sweep and ejection events. In the second region, the contributions of outward and inward interactions are more important than those of sweep and ejec- tion. This shows that the outward and inward events have an important effect on Reynolds stress far from the bed $(y / h>$ $0.55)$. Although near the bed, sweep is more frequent than ejection, by increasing the hole size, the percentage of time occupied by ejection increases compared to that of sweep. Figure $3 \mathrm{a}$ also shows that at the central axis of the flume, the percentage of occurrences of the outward and inward increases when $H$ increases. However, sweep and the ejection events increase and then decrease near the water surface for $0<y / h<0.2$. The larger values of sweep and ejection cause negative sign for $u^{\prime} w^{\prime}$ in quadrant 4 (sweep) and quadrant 2 (ejection), resulting in positive Reynolds stress for $0<y / h<0.55$ at the central axis of the flume, as shown in Figure 2. 
(a)
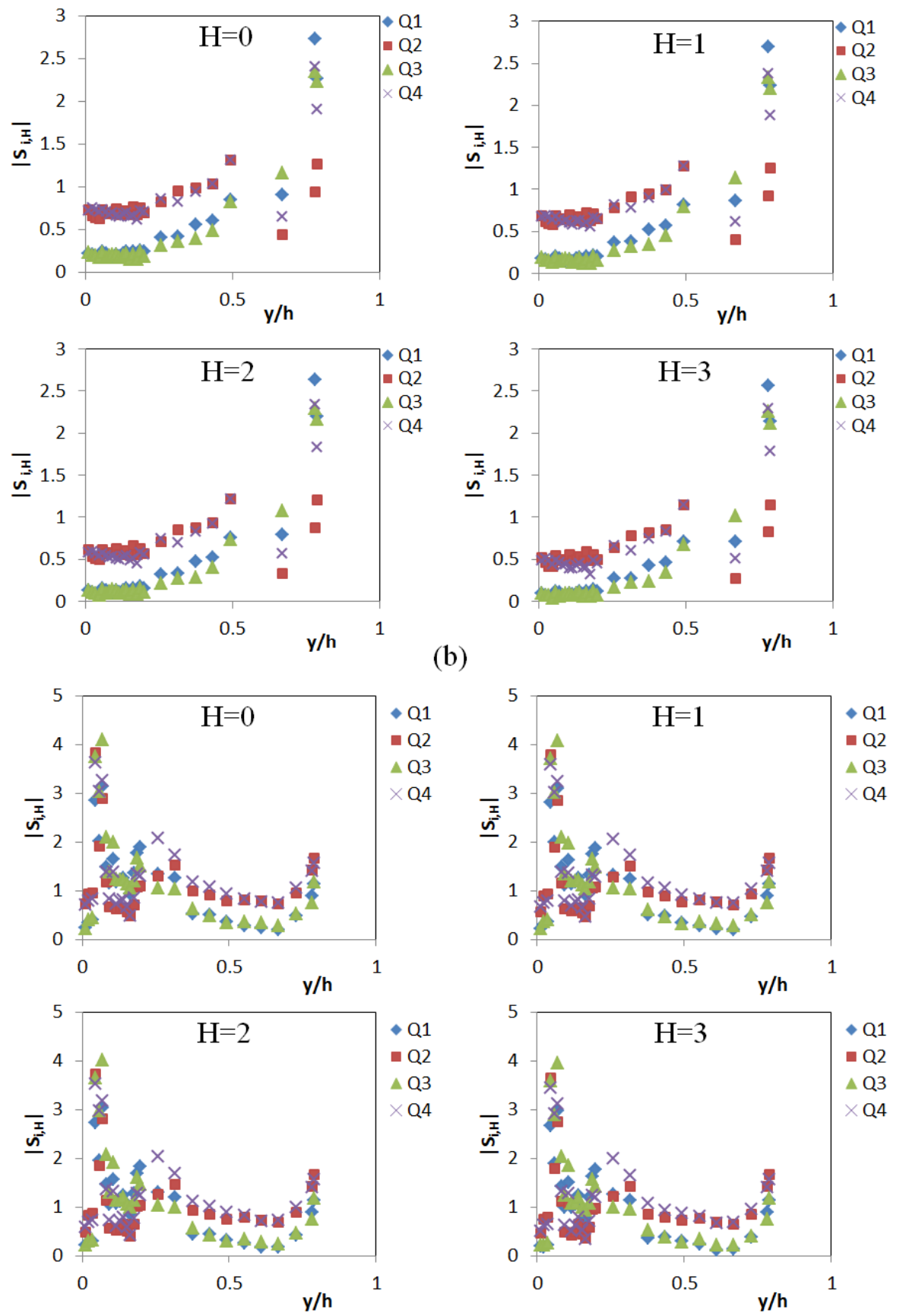

Fig. 4. Stress fraction contributed by each quadrant; a) at the central axis and $b)$ near the vegetated bank $(D=3 \mathrm{~cm})$.

Near the vegetated walls $(D=0.03 \mathrm{~m}$, Figure $3 \mathrm{~b})$ and the bed up to $y / h=0.2$, the sweep and ejection show similar effects for different hole sizes. However, due to the effect of secondary currents and the vegetation, the outward contribution also plays an important role near the bed. Near the water surface (up to the last measured point by ADV), both ejection and outward are dominant events. Also, Figure $3 \mathrm{~b}$ shows that the contribution of ejection and sweep near the vegetated walls decreases toward the water surface up to $y / h=0.75$, while it decreases at the central axis of the flume up to $y / h=0.5$. It seems that turbulence is much less anisotropic near the vegetated walls compared to that along the center of flume, showing contributions in all four quadrants. The effects caused by vegetation, the secondary currents and the FPG flow prevent a decreasing trend of sweep and ejection and an increasing trend of the outward and inward contributions in the region of $y / h<0.5$ for larger hole sizes.

Typically, sweeps exceed ejections by a factor ranging between 1.1 and 2.3. However, values ranging from 3 to 4 (larger sweep-to-ejection ratios) are noticed when turbulence intensities are high, as is commonly observed near plant canopies. Figure 4 presents the contribution of each quadrant to the stress fractions. At the central axis of the flume, with the water depth up to $y / h=$ 0.5 , ejection $\left|S_{2,0}\right|$ and sweep $\left|S_{4,0}\right|$ contribute more to the Reynolds stress with an increasing trend; however, toward the water surface the outward and inward contributions reveal more important role. Also, increase in the hole size leads to different contributions of sweep and ejection with those of the outward and inward near the bed. However, no change is observed near 
the water surface. On the other hand, near both the vegetated wall and the channel bed, considerable scatters are observed with a decreasing trend up to $y / h=0.65$ and then an increasing trend toward the water surface. Accordingly, in the zone near the vegetation and very close to the bed $(y / h<0.1)$ ejection and sweep events are dominant and the Reynolds stress sign is positive, as shown in Figure 2. However, in the zone with a water depth of $0.1<y / h<0.2$, the outward contribution is dominant, and the Reynolds stress has a negative value (see Figure $2)$. Figure 4 also indicates that for a water depth of $y / h>0.2$ and close the vegetated walls $(D=3 \mathrm{~cm})$, the stress fraction receive more contribution by the sweep and ejection. That is why no negative values of Reynolds stress is observed near the water surface and close the vegetated walls, as shown in Figure 2. However, near the water surface at the central axis of the flume, the stress fraction is mainly contributed by the outward and inward contributions (Figure 4) where negative values of Reynolds stress are observed (see Figure 2).

Figures 5a and 5c show the ratio of upward to downward components, $\left|\left(S_{1, \mathrm{H}}+S_{3, \mathrm{H}}\right) /\left(S_{2, \mathrm{H}}+S_{4, \mathrm{H}}\right)\right|$, where $S_{2, \mathrm{H}}$ and $S_{4, \mathrm{H}}$ are negative, called the exuberance ratio (E.R). This ratio is a measurement of the upward momentum transfer against the overall downward flux, showing the exuberant nature of the flow. Comparing Figure 5a to Figure 5c, it is found that this ratio increases from the bed toward the water surface at the central axis of the flume (Figure 5a). However, near the vegetated walls, this ratio increases up to a depth of $y / h=0.2$ and then decreases toward the water surface (Figure $5 \mathrm{c}$ ). The exuberance ratios approaches to zero for E.R $<1$ in Figure 5a, revealing positive sign for Reynolds stress (see Figure 2). However, the values of E.R $>1$ illustrate negative sign for Reynolds stress values near the water surface at the central axis of flume (see Figure 2). On the other hand, the values of E.R $>1$ near the vegetated walls (Figure $5 \mathrm{c}$ ) display the negative signs for Reynolds stress values in Figure 2. In addition Figure 5c shows that for $y / h>0.2$, E.R decreases, leading to positive sign for Reynolds stress values in Figure 2. Comparing Figure $5 \mathrm{~b}$ to Figure $5 \mathrm{~d}$, one can see that near the vegetated walls, the ratio of sweep to ejection is more than 1 excepting very close the bed $(y / h<0.05)$. However, this ratio approaches 1 at the center of flume except near the water surface. Also, by increasing the hole size, the ratio decreased near the bed at the central axis of the flume (Figure 5b), but it increased near the vegetated wall and the minimum ratio is located near the bed (Figure $5 \mathrm{~d}$ ). It is found that the relatively small exuberance values, ranges between about -0.13 and -0.19 , within corn (Shaw et al., 1983). The values range between about -0.3 and -0.8 for $3 \mathrm{D}$ wind velocity components were reported in the canopy with fullyleafed and for wheat (Finnigan, 1979).

\section{DISCUSSION}

The importance of short-lived events of large magnitude is demonstrated by performing a quadrant analysis with an excluded hole region of various sizes. Figure 6a shows the stress fraction $S_{H}^{f}$ (sum of the four quadrant fractions) versus the hole size with the following five water depths $y / h=0.03,0.08,0.13$, 0.37 and 0.65 at the central axis of the flume. As expected, increase in the hole size results in decrease in the sum of the four quadrant fractions $\left(S_{H}{ }^{f}\right)$. The stress fraction decreases more quickly near the bed than near the water surface depending on the change in hole size. It suggests that there are some relatively large magnitude quadrant events occurring near the bed. For $y / h$ $=0.03,0.08$ and 0.13 , about $50 \%$ of the stress is from large magnitude events $(H=5)$. For high values of $y / h(0.37$ and 0.65$)$, the same percentage of the stress is from stronger events $(H \geq 8)$.
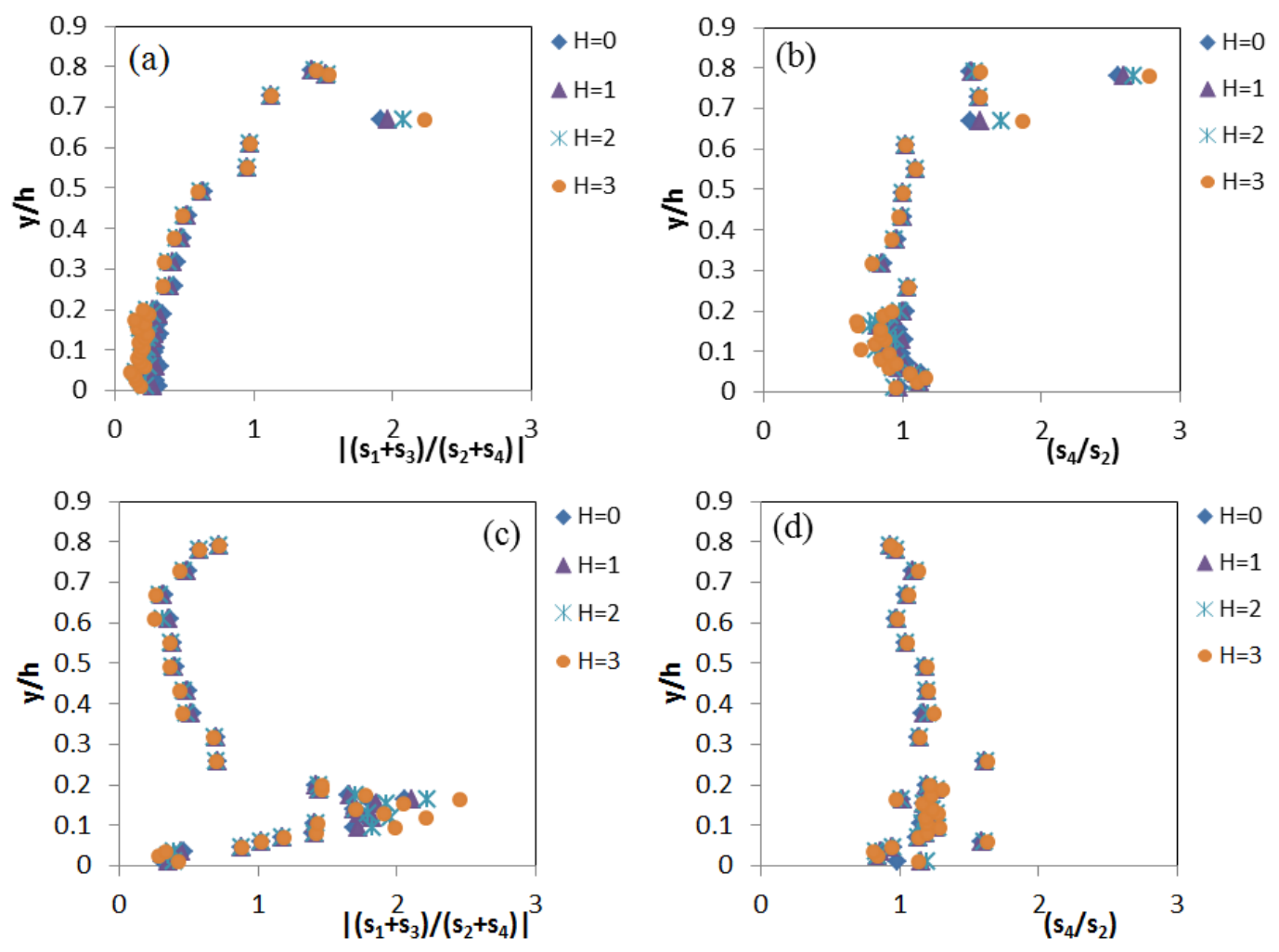

Fig. 5. Event ratios as a function of normalized height.(a) \& (c) Ratio of negative to positive contributions to the momentum flux for central axis (a) and at $D=3 \mathrm{~cm}$ from the vegetated bank (c). And (b) \& (d) ratio of sweeps to ejections for the central axis (b) and $D=3 \mathrm{~cm}$ from the vegetated bank (d). 

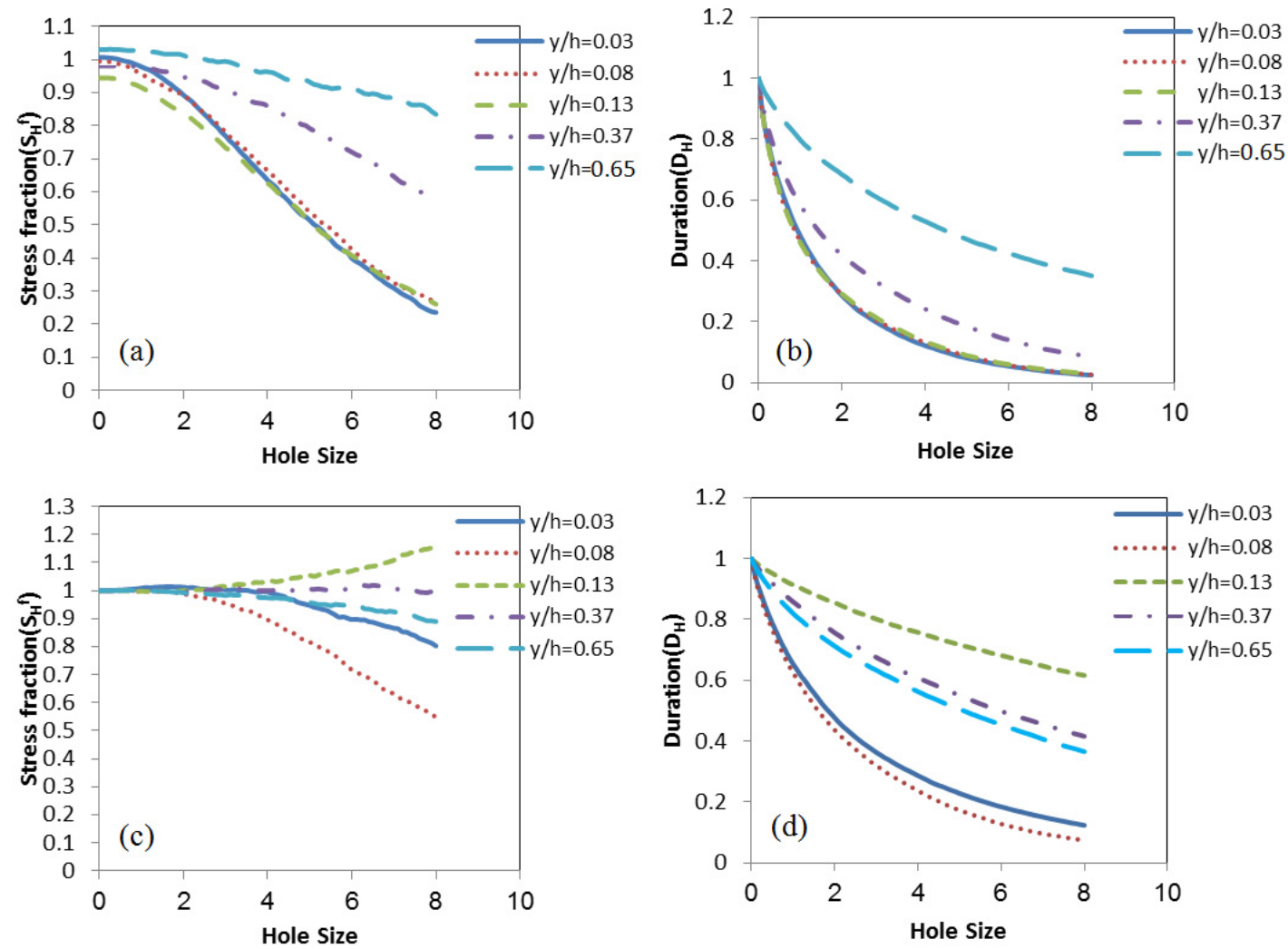

Fig. 6. Sum of all four quadrant fractions with an excluded varying hole size.(a) \& (c) Stress at the central axis (a) and $D=3 \mathrm{~cm}$ from the vegetated bank. And duration for the central axis (b) and at $D=3 \mathrm{~cm}$ from the vegetated bank (d).
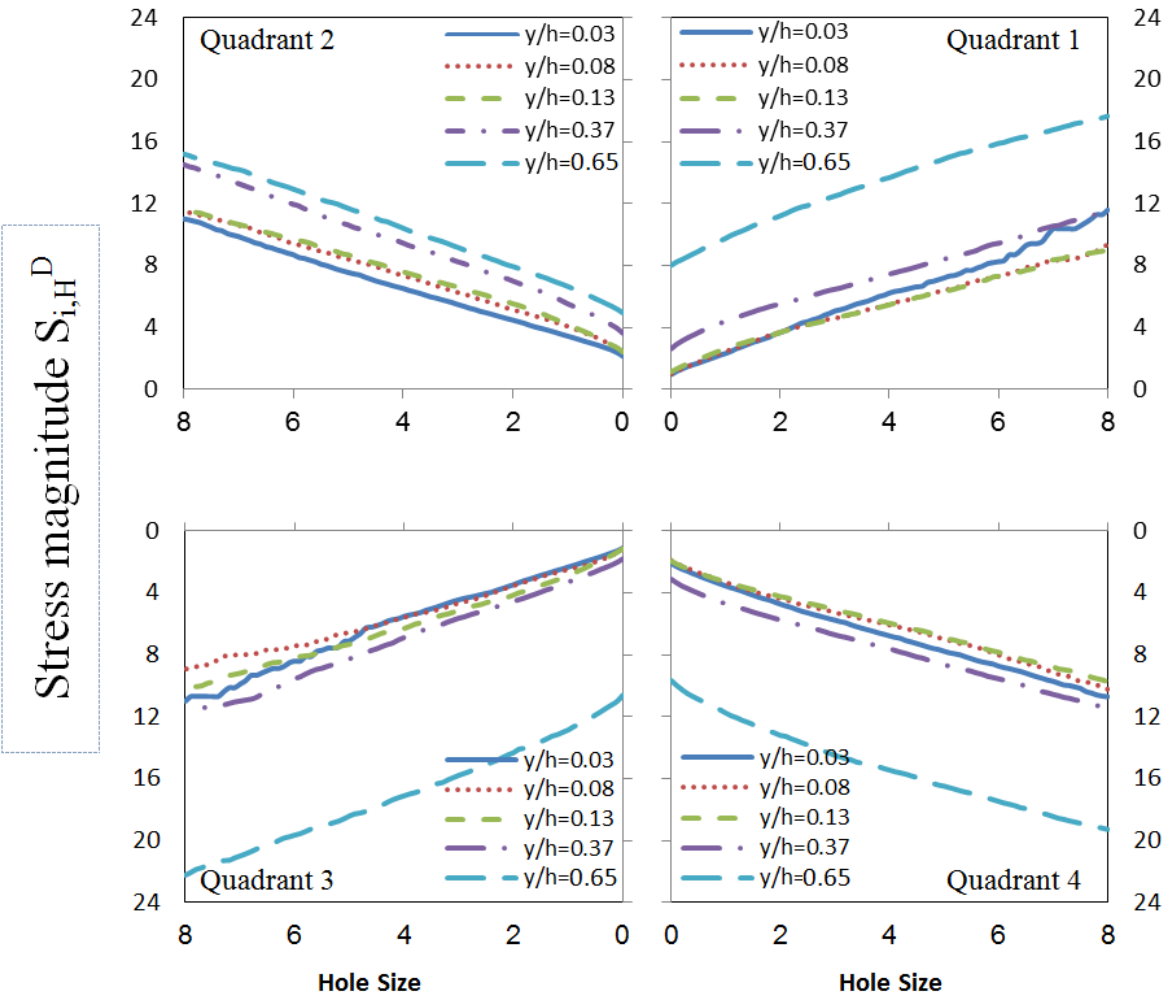

Fig. 7. Stress magnitudes $S_{\mathrm{i}, \mathrm{H}}{ }^{\mathrm{D}}$ at different flow depth $(y / h)$ at the central axis.

Figure 6c shows the stress fraction $S_{H}^{f}$ (sum of the four quadrant fractions) versus the hole size for five different water depths, namely, $y / h=0.03,0.08,0.13,0.37$ and 0.65 near the vegetated walls. Accordingly, the changes in hole size from zero to 2.5 has not a significant effect on the stress fraction $\left(S_{H}^{f}\right)$, but all selected water depths show a decreasing trend for 
the hole sizes more than 2.5 except at $y / h=0.13$. This can also be attributed to negative sign of Reynolds stress at $y / h=0.13$ in Figure 2 .

A measure of intermittency is obtained by considering both stress and time fractions. Figure $6 \mathrm{~b}$ shows the duration $D_{H}$ versus the hole size at the five different water depths at the centerline of flume. The durations at the three lowest water depth $(y / h=0.03,0.08$ and 0.13$)$ drop at almost the same rate with variation of hole size. However, for higher flow depth $(y / h$ $=0.37$ and 0.65 ), the rates of drop in durations due to the changes of $H$ are considerably different. Figure $6 \mathrm{~b}$ shows that a relatively large fraction of the total stress occurs in small durations (fractions of total time). For example, at $H=5$, one half of the stress fraction is due to the events occurring $10 \%$ of the duration for the flow near the bed $(y / h<0.13)$. Similar results were reported in some researches, demonstrating that much of the momentum flux is transported during periods of strong turbulence activity occurring over short durations. This result was not observed for high values of $y / h$ (e.g. $y / h=0.65)$. However, near the vegetated walls and near the bed $(y / h=0.13)$ at $H=5$, most of the stress fraction is due to the events occurring $80 \%$ of duration (Figure $6 \mathrm{~d}$ ).

The quadrant fractions described above do not consider the event duration for finding the signal magnitude for the different quadrant events. The normalized quadrant magnitudes of the momentum flux defined in equation (5) are presented at the center of flume in Figure 7. The magnitudes of the momentum flux gradually augments with the hole size due to short durations at the large hole sizes and the relatively high magnitude of the events. Figure 7 shows that the inward interaction has the largest stress magnitude near the water surface $(y / h=0.65)$ where Reynolds stress has the maximum negative value at the central axis of flume. Also, this figure shows that for large hole sizes near the bed, all of four interactions have nearly the same magnitude. However, for low hole size ejection and sweep, the Reynolds stresses have larger magnitudes. On the other hand, the results illustrate that near the vegetated walls and at $y / h=$ 0.13 where Reynolds stress sign is negative; all four events have large magnitudes with light dominance of the inward and sweep. Near the bed and for the large hole sizes, all of interactions reveal nearly the same magnitude; however, for low hole size, ejection shows the largest stress magnitude; near the water surface, the inwards play dominant role regardless of the hole sizes.

\section{CONCLUSIONS}

Effect of pressure gradient in gravel-bed streams with vegetated banks on flow structure is a challenging problem for river engineers and needs to be considered in practice. To better understand this effect, a laboratory study was conducted in a flume with gravel bed and rice stems over the vertical walls under favorable pressure gradient. Following results were found:

By means of quadrant analysis, detailed statistical features of coherent structures have been investigated. Results of the quadrant analysis clearly demonstrate that all events within a bursting cycle contribute to the flow over gravel bed with vegetated vertical flume walls. For a hole size of $H=0$ and near the gravel bed, the contributions of sweeps and ejections are more important than those of the outward and inward interactions at the central axis of the flume. Near the water surface, however, the effect of the outward and inward interactions clearly dominates.
The changes in hole size cause difference between contributions from sweep and ejection and contribution from the outward and inward near the bed. However, no effect is observed near the water surface. The normalized quadrant magnitudes of the momentum flux augment with the hole size due to short durations at the large hole sizes and the relatively high magnitude of the events.

The stress fraction receives more contribution from the sweep and ejection close the vegetated walls, revealing no negative values of Reynolds stress near the water surface and close the vegetated walls.

The smaller exuberance ratio (E.R) close to zero causes a positive sign of Reynolds stress but illustrates a negative sign for E.R $>1$ and Reynolds stress values near the water surface at the central axis of flume. On the other hand, the positive values of the exuberance ratio (E.R. $>1$ ) near the vegetated walls display negative sign of Reynolds stress.

A relatively large fraction $(50 \%)$ of the total stress occurred in a small fraction of the total duration $(10 \%)$ near the bed and the central axis of flume. However, near the vegetated walls and close to the bed, the majority of the stress fraction is due to the events occurring $80 \%$ of duration.

Results of this research clearly show that the interaction of favorable pressure gradient (accelerating flow) and vegetated banks plays a dominant role on Reynolds stress, turbulence intensities and shear velocity. Application of the present research results will lead to better estimation of several important parameters in river engineering studies including drag coefficient and sediment transport parameters in gravel-bed rivers.

\section{REFERENCES}

Afzalimehr, H., 2010. Effect of non-uniformity of flow on velocity and turbulence intensities in flow over a cobble-bed. Hydrological Processes, 24, 3, 331-341.

Afzalimehr, H., Rennie, C.D., 2009. Determination of bed shear stress using boundary layer parameters in a gravel-bed river. Journal of Hydrological Sciences, 54, 1, 147-159.

Afzalimehr, H., Sui, J., Moghbel, R., 2010. Hydraulic parameters in channels with wall vegetation and gravel bed - field observations and experimental studies. Int. J. Sediment Res., $25,1,81-89$.

Afzalimehr, H., Moghbel, R., Ghalichand, J., Sui, J., 2011. Investigation of Turbulence characteristics in channel with dense vegetation over bed. Int. J. Sediment Res., 26, 3, 255268.

Cellino, M., Lemmin, U., 2004. Influence of coherent flow structures on the dynamics of suspended sediment transport in open-channel flow. ASCE Journal of Hydraulic Engineering, 130, 11, 1077-1088.

Dey, S., Nath, T., 2010. Turbulence characteristics in flows subjected to boundary injection and suction. J. Eng. Mech., 136, 7, 877-888.

Emadzadeh, A., Chiew, Y.M., Afzalimehr, H., 2010. Effect of accelerating flow on incipient motion in a gravel-bed stream. J. Adv. Water Resour., 33, 9, 1094-1104.

Finnigan, J.J., 1979. Turbulence in waving wheat. II. Structure of momentum transfer. J. Boundary- layer Meteorol., 16, 213-236.

Ghisalberti, M., Nepf, H., 2006. The structure of shear layer over rigid and flexible canopies. Environmental Fluid Mechanics, 6, 3, 277-301.

Graf, W.H., Altinakar, M.S., 1993.Hydraulique fluvial. Tome 1. [Fluvial Hydraulics, Vol. 1]. Presses Polytechniqueset Univ. Romandes, Lausanne, Switzerland. 
Graf, W.H., Altinakar, M.S., 2002.Fluvial Hydraulics Flow and Transport Processes in Channels of Simple Geometry. John Wiley and Sons, New York, $681 \mathrm{p}$.

Hurther, D., Lemmin, U., Blanckaert, K., 2002. A field study of transport and mixing in a river using an acoustic Doppler velocity profiler. In: Proceedings of river flow, Louvain-LaNeuve, Belgium.

Jamieson, E.C., Rennie, C.D., Townsend, R.D., 2013. Turbulence and vorticity in a laboratory channel bend at equilibrium clear-water scour with and without stream barbs. ASCE Journal of Hydraulic Engineering, 139, 3, 259-268.

Järvelä, J., 2005. Effect of submerged flexible vegetation on flow structure and resistance. J.Hydrol., 307, 1, 233-241.

Kachwal, L.K., Yanful, E.K., Rennie, C.D., 2012. A semiempirical approach for estimation of bed shear stress in a tailings pond. Environ. Earth Sci., 66, 3, 823-834.

Keylock, C.J., Lane, S.N., Richards, K.S., 2014. Quadrant/octant sequencing and the role of coherent structures in bed load sediment entrainment. J.Geophys. Res. Earth Surf., 119, 2, 264-286.

Kironoto, B., Graf, W.H., 1995. Turbulence characteristics in rough nonuniform open-channel flow. Process Inst. Civ. Eng. Waters Maritime Energ., 112, 316-348.

Leonardi, S., Orlandi, P., Smalley, R.J., Djenidi, L., Antonia, R.A., 2003. Direct numerical simulations of turbulent channel flow with transverse square bars on one wall. J. Fluid Mech., 491, 229-238.

Liu, C., Sui, J., Wang, Z., 2012. Sediment load reduction in Chinese rivers. Int. J. Sediment Res., 27, 7, 521-537.

Lu, S.S., Willmarth, W.W., 1973. Measurements of the structure of the Reynolds stress in a turbulent boundary layer. J. Fluid Mech., 60, 481-511.

Luhar, M., Rominger, J., Nepf, H., 2008. Interaction between flow, transport and vegetation spatial structure.Environ. Fluid Mech., 8, 5, 423-439.
Maity, H., Mazumder, B.S., 2012. Contributions of burst-sweep cycles to Reynolds shear stress over fluvial obstacle marks generated in a laboratory flume. Int. J. Sediment Res., 27, 378-387.

Maity, H., Mazumder, B.S., 2013. Conditional statistics of Reynolds shear stress over obstacle marks. ISH Journal of Hydraulic Engineering, 19, 3, 305-315.

Mazumder, B.S., Ghoshal, D., Pal, K., Ojha, S.P., 2009. Turbulence statistics of flow over isolated scalene and isosceles triangular-shaped bedforms. J.Hydraul. Res., 47, 5, 626-637.

Nakagawa, H., Nezu, I., 1977. Prediction of the contribution to the Reynolds stress from bursting events in open-channel flows. J. Fluid. Mech., 80, 1, 99-128.

Raupach, M.R., 1981. Conditional statistics of Reynolds stress in rough wall and smooth wall turbulent boundary layers. J. Fluid Mech., 108, 363-382.

Rennie,C.D., Millar, R.G., Church, M.A., 2002. Measurement of bed load velocity using an acoustic Doppler current profiler. J.Hydraul. Eng. ASCE, 128, 473-483.

Shaw, R. H., Tavangar, J., Ward, D. P., 1983. Structure of the Reynolds stress in a canopy layer. J. Climate Appl. Meteorol., 22, 1922-1931.

Steiner, A.L., Pressley, S.N., Botros, A., Jones, E., Chung, S.H., Edburg, S. L., 2011. Analysis of coherent structures and atmosphere-canopy coupling strength during the CABINEX field campaign. Atmos. Chem. Phys., 11, 11921-11936.

Song, T., Chiew, Y.M., 2001. Turbulence measurement in nonuniform open-channel flow using acoustic Doppler velocimeter (ADV). J.Hydraul. Eng. ASCE, 127, 3, 219-232.

Yue, W., Meneveau, C., Parlange, M.B., Zhu, W., Hout, R.V., Katz, J., 2007. A comparative quadrant analysis of turbulence in a plant canopy. Water Resour. Res., 43, W05422.

Received 8 August 2014 Accepted 2 February 2015

Note: Colour version of Figures can be found in the web version of this article. 